\title{
A atividade de inteligência no Ministério da Defesa: uma proposta de reforma
}

\section{The intelligence activity in the Ministry of Defense: a proposal for a reform}

Rev. Bra. Est. Def. v. 4, n 1, jan./jun. 2017, p. 17-43

DOI: $10.26792 /$ RBED.v4n 1.2017.72926

ISSN 2358-3932

\section{MARTA SIANES OLIVEIRA DO NASCIMENTO}

IVAN FIALHO

\section{INTRODUÇÃO}

O Ministério da Defesa (MD) foi criado pela Lei Complementar $n^{\circ} 97$ de 10 de junho de $1999^{1}$ que dispõe sobre as normas gerais para a organização, o preparo e o emprego das Forças Armadas (FA). As FA atuam sob a direção superior do Ministério da Defesa, que tem a incumbência de orientar, supervisionar e coordenar as atividades desenvolvidas por essas instituições.

As Forças Armadas, constituídas pela Marinha, pelo Exército e pela Aeronáutica, são subordinadas ao Ministro de Estado da Defesa e dispõem de estruturas próprias. Elas são instituições nacionais permanentes e regulares, organizadas com base na hierarquia e na disciplina, e "destinam-se à defesa da Pátria, à garantia dos poderes constitucionais e, por iniciativa de qualquer destes, da lei e da ordem", conforme determinam o art. 142 da Constituição Federal e o art. $1^{\circ}$ da Lei n ${ }^{\circ}$ 97/1999.

De acordo com a Lei $n^{\circ}$ 97/1999, o Presidente da República, na condição de Comandante Supremo das Forças Armadas, é assessorado pelo Conselho Militar de Defesa, no que concerne ao emprego de meios militares e pelo Ministro de Estado da Defesa, em relação aos demais assuntos pertinentes à área militar. $\mathrm{O}$ Ministro de Estado da Defesa no cumprimento de suas atribuições é assessorado pelo Conselho Militar de Defesa e pelo Estado-Maior Conjunto das Forças Armadas (EMCFA). O Conselho Militar de Defesa (CMD) é composto pelos Comandantes da Marinha, do Exército e da Aeronáutica e pelo Chefe do Estado-Maior Conjunto das Forças Armadas (CEMCFA).

Marta Sianes Oliveira do Nascimento - Escola Superior de Guerra - ESG.

Ivan Fialho - Escola Superior de Guerra - ESG. 
A Lei $n^{\circ}$ 97/1999, em seu art. 11, define que compete ao EMCFA, elaborar o planejamento do emprego conjunto das FA e assessorar o Ministro de Estado da Defesa nos seguintes temas: condução dos exercícios conjuntos e atuação de forças brasileiras em operações de paz; políticas e estratégias nacionais e setoriais de defesa, de inteligência e contrainteligência; assuntos e atos internacionais e participação em representações e organismos, no País e no exterior, na área de defesa; logística, mobilização e tecnologia militar, geoinformação de defesa e aerolevantamento no território nacional; articulação e equipamento das FA; acompanhamento dos setores estratégicos nuclear, cibernético e espacial, além de outras atribuições que lhe forem estabelecidas pelo Ministro de Estado da Defesa. O art. 10 do Anexo I do Decreto 8.978/2017 apresenta essas mesmas competências para o EMCFA.

Neste estudo pretendemos analisar as modificações ocorridas na estrutura organizacional e nas atribuições das áreas relacionadas às atividades de Inteligência Estratégica e de Inteligência Operacional no âmbito do Ministério da Defesa, desde a sua criação, tendo como balizadores a Política Nacional de Defesa (PND)2 a Estratégia Nacional de Defesa (END) e os parâmetros e os limites de atuação da atividade de inteligência e de seus executores no âmbito do Sistema Brasileiro de Inteligência (SISBIN), definidos na Política Nacional de Inteligência (PNI) aprovada pelo Decreto $\mathrm{n}^{\mathrm{o}}$ 8.793de 29 de junho de 2016.

O MD teve sua primeira estrutura regimental definida no Decreto $n^{\circ}$ 3.080, de 10 de junho de 1999. Essa estrutura foi sendomodificada ${ }^{3}$ ao longo dos anos e teve a última alteração aprovada pelo Decreto $\mathrm{n}^{\circ} 8.978$, de $1^{\circ}$ de fevereiro de 2017. Este decreto, no Anexo I - art. $1^{\circ}$, apresenta as atribuições dos órgãos que constituem o MD e os assuntos de sua área de competência, conforme pode ser visualizado no Quadro 1.

A questão a ser tratada é dupla: $1^{\mathrm{a}}$ ) Deve-se juntar os dois níveis da atividade de Inteligência - estratégico e operacional - numa única unidade de inteligência ou mantê-los separados em duas unidades distintas? $2^{\mathrm{a}}$ ) Onde inserir essa(s) unidade(s) na estrutura organizacional do MD, com vistas a otimizar os fluxos de informações correspondentes e o assessoramento da inteligência aos processos decisórios dos escalões de chefia envolvidos? Para atingir esse objetivo, é preciso consideraros diferentes propósitos e o inter-relacionamento da Inteligência Estratégica com a Inteligência Operacional, as necessidades de informações, os conhecimentos a serem produzidos e os clientes a serem atendidos. 


\section{QUADRO 1 - Assuntos de Competência do Ministério da Defesa}

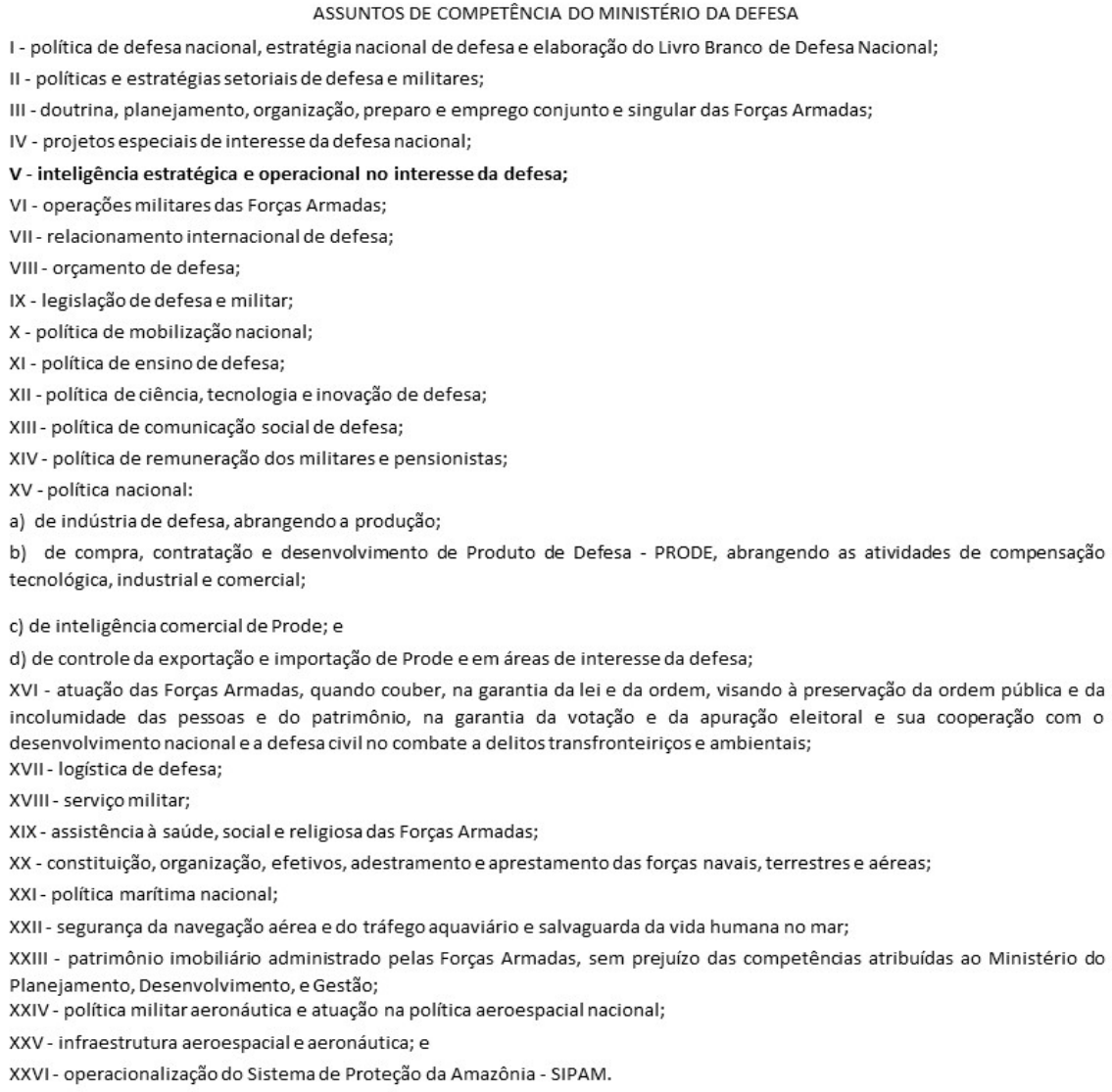

Fonte: Elaborado pelo autor.

Serão apresentadas algumas definições relacionadas à atividade de Inteligência e a evolução da estrutura de Inteligência no MD até a formalização da estrutura atual, adotada desde 2014 por decisão do CEMCFA, com a criação da Subchefia de Inteligência de Defesa (SIDE) - inserida na Chefia de Operações Conjuntas (CHOC) e cujas atribuições envolvem os níveis de Inteligência estratégico e operacional, passando a ser a única unidade de inteligência do MD, subordinada ao EMCFA. 


\section{ATIVIDADE DE INTELIGÊNCIA - ALGUMAS DEFINIÇÕES}

A divisão da atividade de Inteligência no MD em duas estruturas - estratégica e operacional - tem a sua fundamentação nas definições expostas a seguir, abrangendo suas diversas acepções, foco, direcionamento, alcance, objetivos e áreas de atuação.

\section{a. Inteligência Estratégica}

- Aquela necessária à formulação da política (externa) e dos planos militares, nos âmbitos nacional e internacional (Dicionário de Termos Militares e Correlatos do Departamento de Defesa dos EUA, Joint Publication JP 2-01.2, 2017, p. 224).

- Conhecimento referente às possibilidades, vulnerabilidades e linhas de ação prováveis das nações estrangeiras. Busca, principalmente, guiar a formulação e a execução de medidas de segurança nacional, em tempo de paz, e a conduta de operações militares, em tempo de guerra, bem como o desenvolvimento do planejamento estratégico no período de pós-guerra (PLATT, 1974, p.31).

\section{b. Inteligência Tática}

- Aquela necessária ao planejamento e à condução de operações táticas (Dicionário de Termos Militares e Correlatos do Departamento de Defesa dos EUA, Joint Publication JP 2-01.2, 2017, p. 230).

\section{c. Inteligência Operacional}

- Aquela requerida para o planejamento e a condução de campanhas e grandes operações militares voltadas para a conquista de objetivos estratégicos em teatros de combate ou em outras áreas operacionais (Dicionário de Termos Militares e Correlatos do Departamento de Defesa dos EUA, Joint Publication JP 2-0, 2017, p.176).

- Atividade militar especializada, com base em processo mental, permanentemente exercida, com a finalidade de produzir e salvaguardar conhecimento requerido para planejar, conduzir e sustentar operações militares (Glossário das Forças Armadas, 2007 - MD35-G-01, p. 139).

- Aquela "necessária ao planejamento e à condução de campanhas e operações militares das Forças Armadas, no interesse da Defesa Nacional” (Decreto $n^{\circ}$ 4.376/2002, art. 10, sobre a organização e o funcionamento do SISBIN).

O Decreto $\mathrm{n}^{\mathrm{0}}$ 4.376/2002, no art. 10, ao explicitar as atribuições da Agência Brasileira de Inteligência (ABIN),retira das atribuições previstas para a Agência a atividade de Inteligência Operacional, atribuída às FA e competência da área de Defesa Nacional. 


\section{d. Inteligência Militar}

- Conhecimentos sobre quaisquer forças militares estrangeiras, situações ou atividades militares significativas para a doutrina, o planejamento (tático ou operacional) ou a condução de operações e atividades militares (Dicionário de Termos Militares e Correlatos do Departamento de Defesa dos EUA, Joint Publication JP 1-02, 2010, com emendas em 31 Jan. 2011, p.235). É interessante observar que na atualização feita em 2017 não consta o termo Inteligência Militar. Aparece apenas o termo Conselho de Inteligência Militar: fórum de tomada de decisão que formula a política de Inteligência do Departamento de Defesa e estabelece as prioridades (JP 2-O, p.154).

- Atividade de Inteligência de natureza técnico-militar, especializada e permanente que visa a produzir conhecimentos de interesse do comandante de qualquer nível hierárquico e proteger os conhecimentos sensiveis, as instalações e pessoal, contra as ações de serviços de inteligência do oponente ou do inimigo (Glossário das Forças Armadas, 2007 - MD35-G-O1, p. 139).

\section{e. Inteligência de Defesa}

- Entende-se como Atividade de Inteligência de Defesa, aquela desenvolvida no interesse da Defesa, englobando os ramos Inteligência e Contrainteligência (art. $2^{\circ}$ da Portaria Normativa $n^{\circ}$ 295/MD/2002, institui o Sistema de Inteligência de Defesa).

- Atividade de Inteligência, voltada para a produção de conhecimentos de toda ordem, necessária à formulação e à condução, no mais alto nível, do Planejamento Político-Estratégico de Defesa (Defesa Nacional e Inteligência Militar, 2002). ${ }^{4}$

A Inteligência de Defesa compreende conhecimentos abordados nas definições de Inteligência Estratégica, Operacional, Tática e Militar. Conhecimentos sobre a conjuntura nacional e internacional, fatores políticos, econômicos, científico-tecnológicos, psicossociais e as questões militares, sobre o ambiente operacional, as forças hostis, aliadas ou neutras, a população civil na área de combate, a economia, o desenvolvimento tecnológico, a situação político-social do alvo, entre outras, em tempos de paz, conflito ou guerra, são fundamentais para o adequado assessoramento ao Ministro da Defesa em decisões sobre o emprego conjunto das FA e na condução das ações e dos setores estratégicos previstos na END.

Desse modo, embora as definições apresentadas apontem diferenças relativas a objetivos, áreas de atuação, usuários, entre outras categorias, há um verdadeiro entrelaçamento entre as ações descritas, sendo muito difícil traçar um limite preciso entre elas. Todas elas estariam presentes 
no EMCFA em seu papel de assessoramento ao Ministro, com vistas ao processo decisório da Defesa.

Depreende-se daí a necessidade primordial de integração de todos os envolvidos no processo de coleta e busca de informações para produzir conhecimento de inteligência oportuno, objetivo e o mais completo possível, para assessoramento nos assuntos relativos a adestramento e emprego conjunto das FA e, também, naqueles relativos a política, estratégia, assuntos internacionais, inteligência e contrainteligência estratégicas, no interesse da Defesa.

\section{EVOLUÇÃO DA ESTRUTURA DE INTELIGÊNCIA DO MINISTÉRIO DA DEFESA}

Desde a criação do MD em 1999 até 2010, a atividade de Inteligência era descentralizada, estruturada em uma Subchefia de Inteligência no Estado-Maior da Defesa (EMD), órgão de assessoramento ao Ministro da Defesa e no Departamento de Inteligência Estratégica (DIE) da Secretaria Político-Estratégica e de Assuntos Internacionais (SPEAI).

O EMD e a SPEAI estavam ligados diretamente ao Ministro da Defesa, respectivamente, como órgão de assessoramento e como órgão específico singular.

De 1999 até 2010, a Subchefia de Inteligência do EMD, voltada especificamente para a área de Inteligência Operacional, tinha as seguintes atribuições:

I - propor as bases para a doutrina de inteligência e de contrainteligência operacional para operações combinadas;

II - propor diretrizes para o emprego da criptologia no âmbito das Forças Armadas;

III - propor as bases para a doutrina de emprego das atividades de guerra eletrônica, telecomunicações, cartografia, meteorologia e sensoriamento remoto como apoio à atividade de inteligência.

O Departamento de Inteligência Estratégica (DIE/SPEAI) tinha como atribuições:

I - manter o exame corrente da situação estratégica;

II - conduzir a atividade de inteligência estratégica de defesa;

III - acompanhar a evolução dos cenários nacional e internacional, com ênfase nas áreas de interesse estratégico do país;

$I V$-propor diretrizes para orientar a atuação dos adidos de defesa no trato dos assuntos relacionados com a inteligência estratégica;

$V$ - realizar outras atividades inerentes à sua área de atuação. 
Em 2010, o Decreto $n^{\circ} 7.364$ alterou a estrutura organizacional do MD e, entre outras mudanças, extinguiu a SPEAI e modificou a estrutura do EMD, que passou a ser denominado Estado Maior Conjunto das Forças Armadas (EMCFA), permanecendo como órgão de assessoramento do Ministro da Defesa, ao lado do Conselho Militar de Defesa.

A atividade de Inteligência foi centralizada em duas chefias do EMCFA:

1. Chefia de Preparo e Emprego composta pela Assessoria de Inteligência Operacional (AIOp) e por três subchefias: Subchefia de Comando e Controle; Subchefia de Operações; e Subchefia de Logística Operacional.

A AIOp expandiu suas atribuições em relação à sua antecessora (Subchefia de Inteligência do EMD), a saber:

I- propor a doutrina e diretrizes para a atividade de inteligência operacional para operações conjuntas;

II - participar da elaboração do planejamento de emprego conjunto das Forças Armadas, na área específica de inteligência operacional, para cada uma das hipóteses de emprego, previstas na estratégia militar de defesa e acompanhar a condução das operações conjuntas decorrentes;

III - propor a doutrina e diretrizes para emprego da inteligência humana, de sinais e de imagens e das áreas de meteorologia, cartografia, sensoriamento remoto, tecnologia da informação e criptografia, no exclusivo interesse da atividade de inteligência operacional;

$I V$ - coordenar, gerenciar e controlar inovações, implantações e operação de sistemas e recursos tecnológicos que possibilitem o emprego e a integração das inteligências e áreas mencionadas no inciso III como suporte e apoio à atividade de inteligência operacional do EMCFA;

$V$ - conduzir a atividade de inteligência operacional para as operações conjuntas; $e$

$V I$ - realizar outras atividades inerentes à sua área de atuação.

2. Chefia de Assuntos Estratégicos(CAE) composta por três subchefias: Subchefia de Política e Estratégia; Subchefia de Inteligência Estratégica (SCIE); e Subchefia de Assuntos Internacionais. A SCIE incorporou as atribuições do extinto DIE/SPEAI, ampliando sua atuação, mas perdeu a competência de acompanhar a evolução dos cenários nacional e internacional, com ênfase nas áreas de interesse estratégico do país.

Foram definidas como atribuições da SCIE:

I - assessorar o Chefe da CAE, o Chefe do EMCFA e o Ministro da Defesa no exame corrente da situação estratégica;

II - conduzir a atividade de inteligência e contrainteligência estratégica de defesa; 
III - orientar a atuação dos adidos de defesa no trato dos assuntos relacionados com a inteligência de defesa;

IV - coordenar o sistema de inteligência de defesa e efetuar sua ligação ao sistema brasileiro de inteligência;

$V$ - acompanhar a politica nacional de inteligência;

$V I$ - planejar, coordenar e controlar a atividade de contrainteligência e efetuar o credenciamento de segurança da administração central do Ministério da Defesa e órgãos vinculados;

VII - desenvolver capacidade de integração dos conhecimentos, para os fins de defesa, nos campos científico, tecnológico, cibernético, espacial e nuclear;

VIII - propor as bases doutrinárias para o aperfeiçoamento da atividade de inteligência estratégica de defesa, inclusive com a utilização de fontes de imagem e de sinais;

IX - propor estrutura técnica organizacional compatível para a integração de comunicações, criptografia e informações, necessária ao funcionamento do sistema de inteligência de defesa; $e$

$X$ - realizar outras atividades inerentes à sua área de atuação.

O Decreto $n^{\circ} 7.974 / 2013$ mais uma vez alterou a estrutura do MD. Entre outras mudanças, criou o Gabinete do EMCFA, alterou a denominação da Chefia de Preparo e Emprego para Chefia de Operações Conjuntas (CHOC) e da sua Assessoria de Inteligência Operacional para Subchefia de Inteligência Operacional (SCIOp).

As atribuições da $\mathrm{SCIOp} / \mathrm{CHOC}$ continuaram a ser praticamente as mesmas, com algumas modificações na forma de atuação.

As atribuições da SCIE/CAE foram mantidas, voltando a ser de sua competência participar da elaboração e acompanhar a evolução dos cenários nacional e internacional, com ênfase nas áreas de interesse estratégico do país.

Como podemos observar da leitura das atribuições previstas no Decreto $n^{\circ} 7.974 / 2013$ para o EMCFA e para suas duas chefias - CHOC e CAE a atividade de Inteligência, embora centralizada no EMCFA, permaneceu dividida em duas áreas:

- Subchefia de Inteligência Operacional da Chefia de Operações Conjuntas (SCIOp/CHOC), voltada especificamente, entre outras competências, para a elaboração do planejamento de emprego conjunto das FA, na área de Inteligência Operacional (IOp), para cada uma das hipóteses de emprego previstas na END, e para o acompanhamento da condução das operações conjuntas decorrentes.

- Subchefia de Inteligência Estratégica da Chefia de Assuntos Estratégicos (SCIE/CAE), voltada especificamente para o exame corrente da situação estratégica, nacional e internacional, para a produção e a integração de conhecimentos com ênfase nas áreas de 
interesse estratégico do país, a exemplo dos campos científico, tecnológico, cibernético, espacial e nuclear, entre outros.

A SCIE/CAE, como órgão de Inteligência estratégica do MD, também é responsável pelo desenvolvimento da capacidade de integração dos conhecimentos de Inteligência para os fins da defesa e, em decorrência, tem a competência de coordenar o Sistema de Inteligência de Defesa (SINDE) e de efetuar sua ligação com o Sistema Brasileiro de Inteligência (SISBIN).

O SINDE foi criado em 2002, por meio da Portaria n ${ }^{\circ}$ 295/ MD $^{5}$ com vistas a aperfeiçoar a integração e a coordenação da estrutura de Inteligência existente no MD. O SINDE é integrado pelos órgãos de Inteligência de mais alto nível do MD e das Forças Armadas, tendo como órgão central a SCIE/CAE/EMCFA, sem vínculo de subordinação entre seus integrantes. As relações do SINDE estão calcadas em um relacionamento sistêmico.

QUADRO 2 - Composição do SINDE

\begin{tabular}{|c|c|}
\hline Instituição & Órgãos de inteligência \\
\hline Ministério da Defesa & $\begin{array}{l}\text { - Subchefia de Inteligência Estratégica (EMCFA) } \\
\text { - Subchefia de Inteligência Operacional (EMCFA) }\end{array}$ \\
\hline Marinha & $\begin{array}{l}\text { - Subchefia de Estratégia do Estado-Maior da Armada } \\
\text { - Subchefia de Inteligência do Comando de Operações Navais } \\
\text { - Centro de Inteligência da Marinha }\end{array}$ \\
\hline Exército & 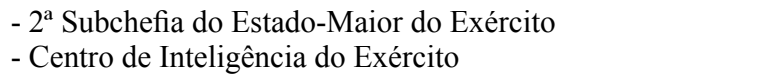 \\
\hline Aeronáutica & $\begin{array}{l}\text { - } 2^{\text {a }} \text { Subchefia do Estado-Maior da Aeronáutica } \\
\text { - Centro de Inteligência da Aeronáutica }\end{array}$ \\
\hline
\end{tabular}

Fonte: Elaborado pelo autor.

O SINDE, como um subsistema do SISBIN, integra as ações de planejamento e execução da Atividade de Inteligência de Defesa, com a finalidade de assessorar o processo decisório no âmbito do Ministério da Defesa (MD) e auxiliar na elaboração dos Planejamentos Estratégicos de Emprego Conjunto das Forças Armadas (PEECFA).

Da mesma forma, a partir de 2006, foram realizados estudos com o objetivo de integrar o nível operacional dos Órgãos de Inteligência (OI), por meio da formulação de doutrina específica sobre a atividade de Inteligência Operacional (IOp) no ambiente de emprego conjunto das FA, e do desenvolvimento de ferramentas tecnológicas nas áreas de guerra eletrônica, cibernética, meteorologia, criptologia, cartografia, sensoriamento remoto e imagens, em apoio às atividades da Inteligência Operacional. 
O Sistema de Inteligência Operacional (SIOP), subsistema do SINDE, integra as ações de planejamento e execução da atividade de Inteligência Operacional, com a finalidade de assessorar o processo decisório no âmbito das Operações Conjuntas, desde o tempo de paz, bem como manter um banco de dados que sirva de base para os Planejamentos Operacionais e para os Comandos Operacionais, quando ativados. O SIOP é integrado pelos órgãos de Inteligência das FA responsáveis pela atividade de Inteligência Operacional, tendo como órgão central a Subchefia de Inteligência Operacional (SIOp) da Chefia de Preparo e Emprego do EMCFA.

É interessante observar que, embora o SINDE represente a integração dos OI no âmbito do MD e integre o SISBIN, não há menção ao SINDE no Decreto $n^{\circ} 4.376 / 2002$ (atualizado em 2015), que dispõe sobre a organização e o funcionamento do Sistema Brasileiro de Inteligência. De acordo com o Decreto, integram o SISBIN os seguintes órgãos representantes do Ministério da Defesa e Forças Armadas: Subchefia de Inteligência Estratégica (SCIE/CAE), Subchefia de Inteligência Operacional (SCIOp/ CHOC), Centro de Inteligência da Marinha (CIM), Centro de Inteligência do Exército (CIE), Centro de Inteligência da Aeronáutica (CIAer), a Divisão de Inteligência Estratégico-Militar da Subchefia de Estratégia do Estado-Maior da Armada e o Centro Gestor e Operacional do Sistema de Proteção da Amazônia (CENSIPAM).

Em julho de 2013, a Chefia do EMCFA entendeu que faltava integração entre as duas unidades de Inteligência do MD e que havia, ao mesmo tempo, uma superposição de tarefas. Instituiu, então, por meio da Portaria no 2.871/EMCFA/MD, de 9 de outubro de 2013, um Grupo de Trabalho (GT), para estudar a integração das áreas de Inteligência do Ministério da Defesa. O GT, composto por representantes da CHOC e da CAE, tinha como objetivos definir os limites e área de atuação, levantar tarefas comuns para evitar duplicidade, integrar a atuação dos dois órgãos de inteligência, no âmbito do MD, no contexto do SISBIN e propor, caso necessário, alterações na estrutura regimental do $\mathrm{MD}$.

O GT elaborou relatório com três linhas de ação, todas com a proposta de fusão da SCIE e da SCIOp em um novo órgão, diferenciadas quanto à subordinação no âmbito do EMCFA: 1) diretamente subordinado ao CEMCFA, 2) subordinado à $\mathrm{CHOC}$ ou 3) subordinado à CAE.

A decisão do CEMCFA foi pela criação de uma nova estrutura - a Subchefia de Inteligência de Defesa (Side) - subordinada à CHOC. Essa solução, em funcionamento desde 2014, foi formalizada oficialmente por meio do Decreto $n^{\circ} 8.978 / 2017$.

O Quadro 3 apresenta a evolução das estruturas relacionadas às atividades de Inteligência Estratégica e Operacional no MD desde a sua criação em 1999, até a situação atual. 


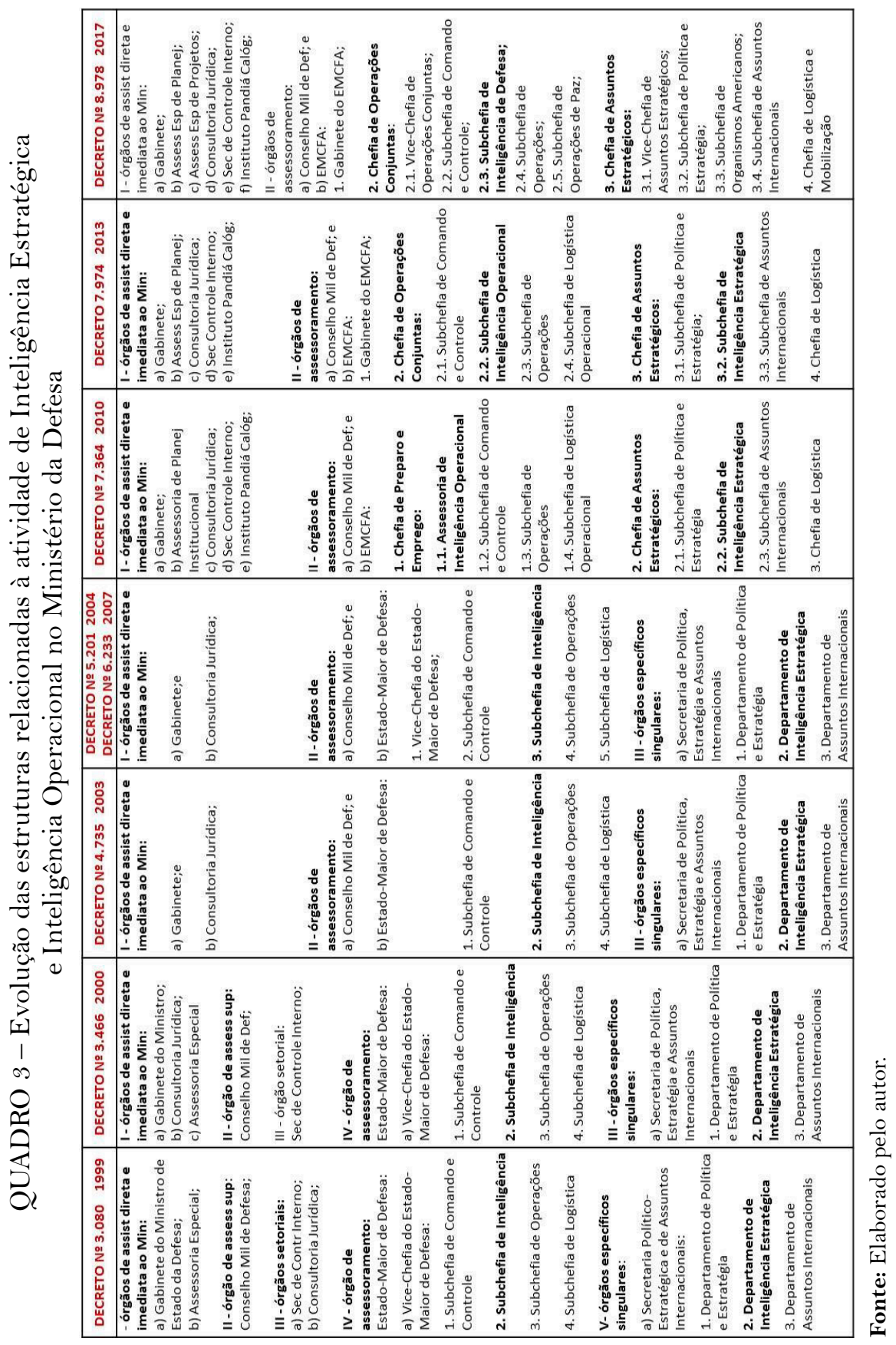




\section{SITUAÇÃO ATUAL DA ÁREA DE INTELIGÊNCIA NO MD: ALGUMAS CONSIDERAÇÕES}

Antes de analisar a decisão do EMCFA de extinguir a SCIOp/CHOC e a $\mathrm{SCIE} / \mathrm{CAE}$ e unificar as áreas de Inteligência Estratégica e de Inteligência Operacional em uma única estrutura - SIDE - subordinada à CHOC, é importante ressaltar alguns pontos, de modo a fundamentar a posição defendida neste ensaio.

- o Ministério da Defesa tem, entre suas áreas de competência,assuntos que extrapolam assuntos militares ou a atuação das Forças Armadas.

- o EMCFA e o Conselho Militar de Defesa são os órgãos de assessoramento ao Ministro da Defesa nas diversas áreas de atuação e nos assuntos previstos na PND e na END, que ultrapassam temas relativos às FA e ao seu emprego em operações conjuntas.

- o Volume 3 do Manual da Doutrina de Operações Conjuntas (MD30-M-01/Vol.3/2011) apresenta os fundamentos da Inteligência para Operações Conjuntas nos planejamentos e na condução de operações militares conjuntas e expõe algumas considerações sobre as necessidades de Inteligência e os níveis de utilização da Inteligência, conforme destacado no Quadro 4. 
QUADRO 4 - Necessidades e Níveis de utilização da Inteligência

\subsection{Necessidades de Inteligência (MD30-M-01, p.12)}

1.6.1 Todos os níveis decisórios necessitam do trabalho da Atividade de Inteligência para minimizar ou eliminar as incertezas que envolvem qualquer processo de tomada de decisão. Dentro desse escopo, os tomadores de decisão e suas respectivas assessorias precisam estabelecer, imperiosamente, qual a abrangência e as prioridades dos requisitos de conhecimentos ou de informações necessários para o devido embasamento a esse processo. Esse é o fundamento mais criterioso que deve ser observado, sob pena do desperdício de meios e de tempo.

1.6.2 No ambiente operacional, mesmo antes do engajamento de forças, os Comandantes (Cmts) necessitarão de respostas às suas indagações para planejar e conduzir operações com sucesso. Algumas respostas são cruciais para a tomada de decisão. Por isso, os Cmts precisam priorizar as suas necessidades perante a Inteligência, dentre as quais incluem-se os Elementos Essenciais de Inteligência (EEI) como os mais críticos para um $\mathrm{Cmt}$ em determinados momentos.

\subsection{Níveis de Utilização da Inteligência (MD30-M-01 p. 21/22)}

3.3.2 O Nível Estratégico tem como foco a produção e a salvaguarda de conhecimentos requeridos para a formulação das avaliações estratégicas que consubstanciarão as políticas e os planos militares no mais alto nível, sob o escopo da Defesa Nacional e orientados para os Objetivos Nacionais. O levantamento permanente de informações sobre as capacidades dos países de interesse, e a sua posterior análise, constituem atribuições prioritárias.

3.3.3 O Nível Operacional tem por finalidade a produção e a salvaguarda de informações e conhecimentos requeridos para planejar, conduzir e sustentar operações militares nesse nível, a fim de que sejam alcançados objetivos estratégicos dentro da área de responsabilidade de um Comando Operacional ativado. Possui o caráter de continuidade no tempo e é utilizado, normalmente, em situação de paz e em situações de conflito, seja na elaboração e aplicação de planos operacionais ou na condução de operações militares. Abrange todos os fatores que condicionam o emprego conjunto de meios terrestres, navais e aéreos.

3.3.4 O Nível Tático produz e salvaguarda informações e conhecimentos limitados, de curto alcance no tempo e dirigidos às necessidades imediatas do comandante tático, seja para o planejamento ou para a condução de operações de combate.

Fonte: Elaborado pelo autor. 
Dessa forma e considerando as definições expostas anteriormente, especialmente as de Inteligência Estratégica e de Inteligência Operacional, entendemos que as duas áreas tratam de matérias diferentes, com objetivos distintos, embora relacionados, interdependentes e até mesmo, complementares. Mas elas não se misturam e por esse motivo devem ficar em estruturas diferentes, bem delimitadas. Colocá-las na mesma unidade, provavelmente, irá limitar a ação de pronto assessoramento ao Ministro da Defesa de maneira adequada, oportuna e completa, especialmente no nível estratégico.

O Decreto $n^{\circ} 8.978 / 2017$ alterou a estrutura e competências da CHOC e da CAE.

- estrutura da Vice-Chefia de Operações Conjuntas da CHOC: Subchefias de Comando e Controle, de Inteligência de Defesa (SIDE), de Operações e de Operações de Paz.

- estrutura da Vice-Chefia de Assuntos Estratégicos da CAE: Subchefias de Política e Estratégia (SCPE), de Organismos Americanos (SCOA) e de Assuntos Internacionais (SCAI). Integram, ainda, a estrutura da CAE os Conselheiros Militares, as Aditâncias de Defesa do Brasil no exterior e a Representação Brasileira na Junta Interamericana de Defesa (RBJID).

Da análise das competências definidas pelo Decreto $n^{\circ}$ 8.978/2017 para a CHOC e, mais especificamente, para a SIDE, pode-se constatar uma mistura dos níveis estratégico e operacional e a ausência de atividades voltadas para o objetivo maior da atividade de Inteligência Estratégica no âmbito da Defesa, que seria assessorar o processo decisório com foco nas questões de Defesa Nacional e Segurança Internacional. O Quadro 5 apresenta um esquema com as áreas de competência da SIDE, tendo como base a unificação das áreas de Inteligência Estratégica e Inteligência Operacional no EMCFA.

Em outras palavras, entendemos que o MD necessita de uma estrutura dedicada exclusivamente à atividade de Inteligência Estratégica para subsidiar o CEMCFA e o Ministro da Defesa na tomada de decisão em questões que abrangem primordialmente política externa, conflitos internacionais, indústria de defesa, ciência e tecnologia, temas estratégicos como os setores nuclear, espacial ou cibernético, entre outras áreas assinaladas na $\mathrm{PND}$, na END e relacionadas às competências do MD. Na atual estrutura do MD isto não está contemplado. 
QUADRO 5 - Esquema com as áreas de competência da SIDE.

\begin{tabular}{|l|l|}
\hline Inteligência & $\begin{array}{l}\text { - Campo Interno: Estratégico e Operacional } \\
\text { - Campo Externo: Estratégico e Operacional }\end{array}$ \\
\hline Contrainteligência & $\begin{array}{l}\text { - Segurança Orgânica } \\
\text { - Segurança Ativa }\end{array}$ \\
\hline Inteligência Tecnológica & $\begin{array}{l}\text { - Sensoriamento Remoto } \\
\text { - Meteorologia } \\
\text { - Centro de Inteligência Operacional (CIOP) } \\
\text { - Inteligência de Sinais } \\
\text { - Inteligência Cibernética }\end{array}$ \\
\hline Posto de Controle & $\begin{array}{l}\text { - Coordenação de processos } \\
\text { - Credenciamento } \\
\text { - Arquivo }\end{array}$ \\
\hline Planejamento e Doutrina & $\begin{array}{l}\text { - Planejamento } \\
\text { - Acompanhamento Doutrinário } \\
\text { - Gestão Orçamentária }\end{array}$ \\
\hline
\end{tabular}

Fonte: Elaborado pelo autor.

A PND define Defesa Nacional como o conjunto de medidas e ações do Estado, com ênfase na expressão militar, para a defesa do território, da soberania e dos interesses nacionais contra ameaças preponderantemente externas, potenciais ou manifestas. Nesse sentido, julgamos que a atividade de Inteligência Estratégica no MD é fundamental e deve estar relacionada com produção/análise/disseminação de conhecimentos para assessorar o processo decisório relacionado primordialmente ao alcance e à manutenção dos Objetivos Nacionais - nas esferas política, econômica, psicossocial, militar e científico-tecnológica - definidos na END.

A CHOC atua fundamentalmente na área da Inteligência Operacional, embora suas atividades estejam vinculadas a ações estratégicas do MD. Seus integrantes necessitam de conhecimentos estratégicos para assessorar o CEMCFA no planejamento e na condução de campanhas e operações militares e subsidiar suas decisões e ações de preparo e emprego das FA em todas as suas possíveis intervenções, para cada uma das hipóteses de emprego apontadas. E aí aparecem as questões da falta de integração de informações e de conhecimentos e da superposição de tarefas observadas nos estudos do GT, criado em julho de 2013.

A integração dos conhecimentos produzidos nos níveis estratégico e operacional, sejam eles oriundos de uma mesma estrutura ou de estruturas diferentes, está diretamente relacionada às capacidades dos usuários de identificar as respectivas necessidades de informação e de direcionar essas 
necessidades para os produtores que, por sua vez, vão analisar os dados obtidos para, finalmente, difundir o conhecimento produzido para quem o solicitou ou dele necessita para a tomada de decisão.

O adequado fluxo de informação é uma questão de gestão da comunicação, considerando a "necessidade de conhecer",que define a obrigação de compartimentar ou a importância de compartilhar o conhecimento. As estruturas de Inteligência podem estar em áreas diferentes e, mesmo assim, haver um fluxo de informação oficial, que compartilhe e integre aquilo que precisa ser integrado e compartilhado. Por outro lado, podem estarem uma mesma área ou setor, onde os produtores da informação/ conhecimento não conversam, não interagem, não compartilham e não integram suas informações/conhecimentos. Isto é, queremos deixar bem claro que um fluxo de informações e conhecimentos será mais ou menos integrado, coerente e consistente em função da qualidade da gestão do ciclo de inteligência e não da posição unificada ou separada das unidades ou estruturas de inteligência, no presente caso, estratégica e operacional.

É importante ressaltar a importância do fluxo de informações/conhecimentos da área de Inteligência Estratégica para a área de Inteligência Operacional, para subsidiar a área de planejamento e execução de operações conjuntas com conhecimentos, por exemplo, sobre a situação internacional, a conjuntura do entorno estratégico, a situação de acordos e tratados, inovações tecnológicas em FA estrangeiras, entre outros temas de acompanhamento e, em última análise, para assessorar o CEMCFAe o Ministro da Defesa quanto ao emprego da FA em operações conjuntas.

Além disso, a área de Inteligência Estratégica também precisa manter um fluxo de informações com outras áreas da CAE, proporcionando informações oportunas e relevantes, integrando os conhecimentos de inteligência em diversos campos, para os fins de defesa, realizando avaliações da conjuntura e a avaliação estratégica de Inteligência de Defesa para assessoramento ao Chefe da CAE, ao CEMCFA e ao Ministro de Estado da Defesa, especialmente no exame corrente da situação estratégica e na condução dos assuntos internacionais que envolvam o MD. Nesse enfoque, é importante ressaltar que as informações/conhecimentos de Inteligência estratégicos produzidos pelo MD,órgão integrante do SISBIN, devem ser compartilhados com a ABIN, responsável por subsidiar o processo decisório nacional de alto nível.

Com objetivos, necessidades, áreas de atuação e focos tão diferentes, é difícil compreender que possa haver duplicidade ou superposição de tarefas das áreas de Inteligência Operacional e Estratégica no âmbito do EMCFA. Um trabalho de mapeamento dos processos envolvidos em cada atribuição 
prevista, definindo claramente quem faz o quê e de que forma e como as atividades se integram e complementam poderia resolver o problema.

Como já foi ressaltado anteriormente, o MD não se resume a operações conjuntas, tendo atribuições muito mais amplas. Ações estratégicas previstas na END como mobilização; relacionamento internacional de defesa;comunicação social e desenvolvimento de uma mentalidade de defesa; (in)dependência da indústria de defesa de tecnologias e conhecimentos estrangeiros; acompanhamento do desenvolvimento dos setores espacial, nuclear e cibernético no mundo, de interesse da defesa, entre outras, exigem coleta, busca, produção e processamento de dados, informações e conhecimentos, inerentes à atividade de Inteligência, especialmente da vertente estratégica. E aqui, cabe mais uma vez ressaltar que os dois níveis da Inteligência de Defesa - estratégico e operacional -, embora apresentem uma zona de interseção, não se confundem.

Nesse contexto, consideramos inadequado reunir as atribuições de Inteligência Estratégica e de Inteligência Operacional na $\mathrm{CHOC} /$ EMCFA.A criação de uma única unidade de Inteligência no MD - a SIDE - inserida na CHOC/EMCFA priva o MD de uma área realmente voltada para a Inteligência Estratégica.

Essa decisão dirige o foco da Inteligência para a produção/análise de conhecimentos que interessam às operações conjuntas, deixando as demais áreas de competência do MD bastante desprovidas. A natureza corrente da Inteligência Operacional e sua premente demanda, em função, principalmente, do planejamento e monitoração das operações conjuntas relativas ao adestramento e ao emprego real e frequente das forças singulares na garantia da lei e da ordem (GLO), como tem ocorrido nos últimos anos, acarretam uma perda de prioridade nas análises da conjuntura, próprias da inteligência estratégica, mas distantes do dia a dia dos integrantes da CHOC.

Dessa forma, oEMCFA tem reduzida sua capacidade de assessorar o Ministro de Estado da Defesa em decisões estratégicas para o país, competência prevista na descrição de suas atribuições. Em consequência, o processo decisório nacional, naquilo que se refere aos assuntos de Defesa fica, também, prejudicado.

\section{PROPOSTA DE SOLUÇÃO: CRIAÇÃO DA ASSESSORIA DE INTELIGÊNCIA ESTRATÉGICA}

Propomos a criação de uma Assessoria de Inteligência Estratégica (AIE), diretamente vinculada ao CEMCFA, tendo em vista a modernização da estrutura do MD, o cumprimento das atribuições impostas ao Ministério e às diretrizes emanadas da PND. 
Essa proposta encontra respaldo nos artigos $1^{\circ}$ e $2^{\circ}$ do Decreto $n^{\circ}$ 8.978/2017, que apresenta as áreas de competência do MD e define o EMCFA como órgão de assessoramento e no próprio conceito de atividade de Inteligência apresentado na Política Nacional de Inteligência (2016).

Exercício permanente de ações especializadas, voltadas para a produção e difusão de conhecimentos, com vistas ao assessoramento das autoridades governamentais nos respectivos níveis e áreas de atribuição para o planejamento, a execução, o acompanhamento e a avaliação das políticas de Estado. (BRASIL, 2016).

Também encontra fundamento nas definições de Sherman Kent (1967), Abraham Shulsky e Gary Schmitt (2002), que apresentam uma concepção trina de Inteligência: produto (conhecimento), processo (atividade) e organização (estrutura de Inteligência). Esses autores destacam a necessidade que autoridades, civis e militares, têm de informações estratégicas para salvaguardar o bem-estar nacional e sua importância no processo decisório, seja no campo militar seja nas altas esferas da Administração Pública.

As informações estratégicas, principalmente do exterior, de acordo com Kent (1967), referem-se aos conhecimentos necessários à defesa do país e de seus interesses que dão embasamento para a definição da política nacional de alto nível em relação a outros Estados. O levantamento de informações sobre as capacidades, políticas, objetivos, interesses e vulnerabilidades dos países de interesse, a atualização dessas informações e a sua posterior análise, são as atribuições prioritárias e permanentes da Inteligência Estratégica, com vistas à política externa, e não se confundem com as atribuições da área de Inteligência Operacional.

Escolher que áreas acompanhar e em que profundidade vai depender dos objetivos e interesses nacionais e das ameaças envolvidas. $\mathrm{O}$ produto da Inteligência Estratégica é resultante de um método técnico-científico de raciocínio, de um processo lógico, que vai desde a observação e acompanhamento dos fatos, reunião, processamento, integração, análise, avaliação das variações ocorridas, até a difusão dos conhecimentos aos utilizadores.

Inteligência Estratégica não é, portanto, uma atividade trivial, que pode ser realizada por um profissional qualquer que se encontra disponível em dado momento e que tem outras atribuições. Requer de seus profissionais, segundo Kent (1967), domínio dos assuntos em foco, da política externa e dos problemas estratégicos correntes, imparcialidade ante novos argumentos, engenhosidade no desenvolvimento de processos de pesquisa, imaginação para formular hipóteses e análise aguçada, sabedoria na apresentação das conclusões e cuja capacidade técnica esteja devotada à produção de informes úteis aos referidos problemas; não basta ter conhecimento especia- 
lizado, mas é preciso conhecer e dar significado ao conhecimento produzido. A atividade de Inteligência Estratégica requer de seus elaboradores o melhor treinamento profissional, alta capacidade intelectual e uma grande visão do panorama mundial. Segundo Mark Lowenthal (2009), também seguidor da concepção trina de Kent, Inteligência seria o processo (atividade) pelo qual certos tipos de informação importantes para a segurança nacional são requeridos, coletados, analisados e disponibilizados aos tomadores de decisão. Inteligência (produto) seria, portanto, a informação voltada às necessidades dos tomadores de decisão. $\mathrm{O}$ autor destaca pelo menos quatro objetivos para uma organização de Inteligência: evitar surpresas estratégicas; fornecer avaliações de longo prazo; assessorar o processo decisório; e proteger (manter o sigilo) suas informações, necessidades e métodos.

Assim, somente uma organização com uma estrutura especializada pode se desincumbir de tarefa tão complexa e proporcionar condições para que seus profissionais possam produzir conhecimentos que satisfaçam às necessidades dos utilizadores, fornecendo informações seguras, completas e oportunas.

Inteligência Estratégica envolve, portanto, uma atividade especializada, direcionada para a obtenção de informações de alto nível, especialmente do exterior, necessárias à defesa do país e à conquista de seus objetivos estratégicos. Essas informações vão subsidiar o planejamento e desenvolvimento de políticas de Estado, a análise do potencial e intenções de outros Estados,como também as políticas de resposta e proteção, empreendidas para contrabalançar as ações de outros Estados que podem se opor às aspirações nacionais. Envolve, por exemplo, definir a estatura estratégica ${ }^{7}$ de cada país em questão, analisar o potencial de guerra (força militar ativa e mobilizável), o peso e eficiência dos instrumentos não militares de política e estratégia, as vulnerabilidades específicas do(s) país(es) considerado(s),entre outras informações que permitam descrever o passado, o presente e o futuro, delineando prováveis linhas de ação do país oponente e as necessárias ações preventivas e reativas para o alcance dos objetivos e interesses nacionais.

Nesse contexto, propomos como competências da AIE o resultado da combinação do que foi definido para a SCIE/CAE, nos incisos I, II, III, IV, V e VI do art. 18 do Decreto $n^{\circ} 7.974 / 2013$, já revogado, acrescido dos incisos II, III, IV, V e XVI do art. 15 do Decreto $n^{\circ}$ 8.978/2017, que trata das atribuições da SIDE/CHOC, conforme exposto a seguir:

I - assessorar o Ministro de Estado da Defesa e o Chefe do Estado-Maior Conjunto das Forças Armadas nos assuntos referentes à inteligência, com enfoque em temas estratégicos do interesse da defesa;

II - assessorar o Ministro da Defesa, quando cabível, na condução de assuntos internacionais referentes à inteligência de defesa; 
III - atender às demandas das Chefias do Estado-Maior Conjunto das Forças Armadas e dos demais órgãos da estrutura organizacional do Ministério da Defesa, referentes à produção de conhecimentos de inteligência de defesa, no nível estratégico;

IV - acompanhar a conjuntura nacional e internacional e realizar a integração dos conhecimentos de inteligência com vistas a subsidiar o EMCFA no planejamento do preparo e emprego das FA;

$V$-realizar a integração dos conhecimentos de inteligência, para os fins de defesa, nos campos científico, tecnológico, cibernético, espacial e nuclear;

VI - participar da elaboração e acompanhar a evolução dos cenários nacional e internacional, com ênfase nas áreas de interesse estratégico do país;

VII - orientar a atuação dos Adidos de Defesa, em coordenação com a Chefia de Assuntos Estratégicos, em assuntos relacionados com a inteligência de defesa;

VIII - elaborar as avaliações de conjunturas e a Avaliação Estratégica de Inteligência de Defesa para a atualização da Política, da Estratégia e da Doutrina Militar de Defesa;

IX-propor as bases doutrinárias para o aperfeiçoamento da atividade de inteligência estratégica de defesa;

$X$ - participar do processo de atualização da Política Nacional de Inteligência.

Propomos, ainda, acrescentar às atribuições do EMCFA: assessorar o Ministro de Estado da Defesa na análise política e estratégica da segurança internacional e da defesa nacional. Essa competência, prevista no art. $8^{\circ}$, inc. I do Decreto $n^{\circ} 8.978 / 2017$, está atribuída, equivocadamente, desde 2013, ao Instituto Pandiá Calógeras, órgão de assistência direta ao ministro, dedicado a pesquisas e estudos acadêmicos. Entendemos que a tarefa de análise política e estratégica da segurança internacional e da defesa nacional está relacionada à competência de assessoramento do EMCFA, por meio das avaliações realizadas pela SCPE/CAE e dos conhecimentos produzidos pela AIE.

A criação da AIE também traz implicações para o relacionamento e fluxo de informações entre diversas unidades do MD, destacando-se:

- o SINDE como subsistema do SISBIN, teria como órgão central a AIE/EMCFA;

- o SIOp, subsistema do SINDE, integrado pelas agências correspondentes de Inteligência Militar das forças singulares, teria como órgão central a SIDE - área de Inteligência Operacional da CHOC/ EMCFA;

- o SIOP, tendo em vista o envolvimento nas decisões sobre o emprego das FA em ações diversas, dentro da perspectiva da Inteligência Operacional, também deve integrar o SISBIN; 
- a Assessoria Especial de Planejamento (ASPLAN) do MD deve estar inserida no fluxo de informações da AIE, especialmente no que se referea conhecimentos para subsidiar estudos e ações relativas ao Sistema de Planejamento Estratégico de Defesa (SISPED);

- a Subchefia de Política e Estratégia (SCPE/CAE) deve estar inserida no fluxo de informações relacionado à avaliação da conjuntura. Nesse caso, a AIE difundiria também para a SCPE, conhecimentos sobre a conjuntura regional e internacional para subsidiá-la na avaliação da situação estratégica e dos cenários nacional e internacional, de interesse do país;

- a SIDE/CHOC deve estar inserida no fluxo de informações da AIE. A SIDE seria usuária e demandante de conhecimentos integrados/ produzidos pela AIE relativos à conjuntura regional e internacional com vistas a subsidiar o planejamento do preparo e emprego das FA;

- a SIDE, no que tange à produção de conhecimentos, seria responsável pelo acompanhamento da conjuntura nacional, especialmente para assessorar quanto ao emprego das FA nas ações de GLO, de segurança das fronteiras, de apoio à segurança em grandes eventos, entre outras, para as quais as FA são chamadas a apoiar;

- a SIDE teria ainda como missão integrar os conhecimentos produzidos pelas agências de Inteligência das forças singulares e difundir para a AIE, aquilo que for do interesse da área de Inteligência Estratégica.

O que importa salientar é a diferença entre as ações da Inteligência Operacional - que tem seu foco no planejamento e na condução de campanhas e operações militares das FA - e o acompanhamento de fatos, análise, produção e difusão de conhecimentos para subsidiar o processo decisório, ações da Inteligência Estratégica, cuja abrangência ultrapassa as fronteiras do MD e envolve vários atores da esfera do Estado, além das FA. Isto não quer dizer, no entanto, que essas atividades sejam estanques. É imprescindível um constante fluxo de informações e conhecimentos entre as unidades do EMCFA (CHOC e CAE) e sua Assessoria de Inteligência Estratégica, sem haver duplicidade ou sobreposição de tarefas.

Para reforçar nossos argumentos a respeito da necessidade de um melhor assessoramento de Inteligência ao Ministro da Defesa, convém frisar que o Sistema Nacional de Defesa inclui diversos ministérios, sendo o MD a instituição central. Desse modo, a Defesa Nacional transcende assuntos militares, envolvendo, também, questões econômicas, diplomáticas, educacionais, tecnológicas, ambientais, humanas, territoriais e de saúde. 
A minuta da Política Nacional de Defesa (PND), encaminhada para a apreciação do Congresso Nacional em novembro de 2016, afirma que a concepção da estrutura de Defesa brasileira abarca o desenvolvimento das potencialidades de todos os segmentos do país, considerando os Objetivos Nacionais Fundamentais, ${ }^{8}$ a política externa brasileira, as políticas setoriais do país, bem com a sua situação socioeconômica, sua extensão territorial e outros aspectos relevantes. Define, ainda que a complexidade do tema demanda que as ações do MD se articulem com as de outros órgãos de Estado e da sociedade brasileira. A Estratégia Nacional de Defesa (END), de uma certa forma, orienta diversos setores e segmentos do Estado brasileiro quanto às medidas a serem implementadas para atingir os Objetivos Nacionais de Defesa (OND), estabelecidos na PND. É fundamental, portanto, a interação e a cooperação de diversos setores e suas correspondentes atividades que, embora não estejam diretamente ligados à Defesa ou às FA, estão relacionados com a manutenção do bem-estar e da segurança da população em seu sentido mais amplo.

O conhecimento de Inteligência produzido no âmbito do MD, especialmente em sua vertente estratégica, além de auxiliar o processo decisório do próprio MD,tem a $\mathrm{ABIN}$ como cliente, uma vez que a $\mathrm{ABIN}$, órgão responsável pela Inteligência de Estado do Brasil, atua diretamente na produção de conhecimentos para subsidiar a correta tomada de decisão pela Presidência da República e por seus ministérios.

Cada órgão integrante do SISBIN atua na obtenção, produção e compartilhamento de informações no âmbito de sua área de competência e auxilia a produção conjunta de conhecimentos de Inteligência. A ABIN, órgão central do SISBIN ${ }^{8}$ coordena o processo de obtenção e análise de informações, além da produção de conhecimentos de Inteligência necessários ao processo decisório nacional.

Neste estudo buscamos ressaltar a importância e a necessidade de uma área específica para a atividade de Inteligência Estratégica, responsável pela produção de conhecimentos que permitam ao EMCFA cumprir sua missão de assessorar o Ministro da Defesa, conforme previsto no Decreto $n^{\circ} 8.978 / 2017$, especialmente nos temas definidos nas diretrizes da PND e nas ações estratégicas da END.

O MD deve cuidar tanto da Estratégia de Defesa quanto da Inteligência de Defesa. Hoje, o EMCFA está absorvendo essas duas áreas, em detrimento das demais unidades do MD, inclusive do próprio Gabinete do Ministro. Em relação a essas questões, julgamos que do ponto de vista epistemológico e histórico, a Estratégia e a Inteligência Estratégica são campos de conhecimentos interligados, mas distintos, assim como as atuações do estrategista que decide e do analista de inteligência que o assessora. 
Pensamos, finalmente, que os estudos para consolidar a proposta de criação da Assessoria de Inteligência Estratégica no EMCFA intensificaram uma reflexão que merece ser aprofundada: todas as áreas do MD precisam do assessoramento de Inteligência Estratégica e de conhecimentos relativos à análise político-estratégica nos seus processos decisórios. A Defesa como função pública de Estado tem um caráter holístico que transcende a visão militar, conquanto esta seja a predominante.

Nesse contexto de proposta de reforma do MD, surgem, ainda, outras duas questões que, com certeza, demandarão estudos mais complexos: a Inteligência Estratégica de Defesa e a Estratégia de Defesa, componentes da Grande Estratégia do país no âmbito internacional, devem ficar a cargo exclusivo do EMCFA? As áreas de Inteligência Estratégica e de Política e Estratégia devem ficar subordinadas ao EMCFA?

Outrossim, salienta-se que nenhuma proposta de mudança é neutra ou isenta de possíveis contradições. Nenhuma mudança deve ser definitiva, devendo ser aperfeiçoada e atualizada sempre que necessário.

\section{REFERÊNCIAS}

Brasil. 1988. Constituição da República Federativa do Brasil. Brasília: Senado.

1999. Lei Complementar $n^{\circ} 97$ de 10 de junho de 1999. Dispõe sobre as normas gerais para a organização, o preparo e o emprego das Forças Armadas (FA). Disponível em: http://www2.camara.leg.br. Acesso em 15 ago. 2016.

. 1999. Lei no 9.883 de 07 de dezembro de 1999. Institui o Sistema Brasileiro de Inteligência, cria a Agência Brasileira de Inteligência - ABIN, e dá outras providências. Disponível em: http://www.abin.gov.br. Acesso em 13 jul. 2016.

.2000. Decreto $n^{\circ}$ 3.466 de 17 de maio de 2000. Aprova a Estrutura Regimental do Ministério da Defesa e dá outras providências. Disponível em: http://www2. camara.leg.br. Acesso em 15 ago. 2016.

. 2002. Decreto $n^{\circ} 4.376$ de 13 de setembro de 2002. Dispõe sobre a organização e o funcionamento do Sistema Brasileiro de Inteligência, instituído pela Lei ${ }^{\circ}$ 9.883, de 7 de dezembro de 1999, e dá outras providências. Disponível em: http:// www.abin.gob.br. Acesso em 12 fev.2017.

. 2003. Decreto $n^{0} 4.735$ de 11 de junho de 2003. Aprova a Estrutura Regimental do Ministério da Defesa e dá outras providências. Disponível em: $\underline{\text { ht- }}$ tp://www2.camara.leg.br. Acesso em 15 ago. 2016. 
. 2004. Decreto $n^{0} 5.201$ de 2 de setembro de 2004. Aprova a Estrutura Regimental do Ministério da Defesa e dá outras providências. Disponível em: $\underline{\text { ht- }}$ tp://www2.camara.leg.br. Acesso em 15 ago. 2016.

. Ministério da Defesa. 2007. Portaria Normativa $n^{\circ}$ 196/EMD/MD, de 22 de fevereiro de 2007. Aprova o "Glossário das Forças Armadas" - MD35-G-01. 4. ed. Disponível em: http://www.defesa.gov.br/arquivos/File/legislacao/emcfa/ publicacoes/md35g01glossario fa4aed2007.pdf. Acesso em 3 jul. 2016.

. 2007. Decreto $n^{\circ}$ 6.233, de 4 de outubro de 2007. Aprova a Estrutura Regimental do Ministério da Defesa, altera o Decreto no 3.564, de 17 de agosto de 2000, que dispõe sobre a estrutura e o funcionamento do Conselho de Aviação Civil - CONAC, e dá outras providências. Disponível em: http://www2.camara. leg.br. Acesso em 15 ago. 2016.

. 2010. Lei Complementar $n^{\circ} 136$, de 25 de agosto de 2010. Altera a Lei Complementar $n^{\circ}$ 97, de 9 de junho de 1999, para criar o Estado-Maior Conjunto das Forças Armadas e disciplinar as atribuições do Ministro de Estado da Defesa. Disponível em: http://www2.camara.leg.br. Acesso em 15 ago. 2016.

. 2010. Decreto $n^{\circ} 7.364$, de 23 de novembro de 2010. Aprova a Estrutura Regimental do Ministério da Defesa e dá outras providências. Disponível em: http://www2.camara.leg.br. Acesso em 15 ago. 2016.

. Ministério da Defesa. 2011. Portaria Normativa $n^{\circ}$ 3.810/MD, de 8 de

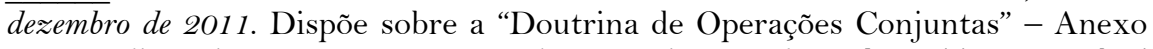
D - Inteligência para Operações Conjuntas. Disponível em: http://www.esg.br/ images/manuais. Acesso em 24 out. 2016.

. Ministério da Defesa. 2012. Estratégia Nacional de Defesa. Brasília, 2012. Disponível em: http://www.defesa.gov.br/arquivos/estadoedefesa/END-PND. Acesso em 8 abr. 2016.

. Ministério da Defesa. 2012. Política Nacional de Defesa. Brasília, 2012. Disponível em: http://www.defesa.gov.br/arquivos/estadoedefesa/END-PND. Acesso em 8 abr.2016.

.2013. Decreto $n^{\circ} 7.479$, de $1^{\circ}$ de abril de 2013. Aprova a Estrutura Regimental e o Quadro Demonstrativo dos Cargos em Comissão e Funções de Confiança do Ministério da Defesa. Disponível em: http://www2.camara.leg.br. Acesso em 15 ago. 2016.

. 2013. Decreto Legislativo $n^{\circ} 373$, de 2013. Aprova a Política Nacional de Defesa, a Estratégia Nacional de Defesa e o Livro Branco de Defesa Nacional. 
Disponível em: http://www2.camara.leg.br/legin/fed/decleg/2013/decretolegislativo-373-25-setembro2013. Acesso em 3 jul.2016.

.2016. Decreto $n^{\circ} 8.793$, de 29 de junho de 2016. Fixa a Política Nacional de Inteligência. Disponível em: http://www.planalto.gov.br/ccivilo3. Acesso em 03 jul. 2016.

. 2017. Decreto $n^{\circ} 8.978$, de $1^{\circ}$ de fevereiro de 2017. Aprova a Estrutura Regimental e o Quadro Demonstrativo dos Cargos em Comissão e das Funções de Confiança do Ministério da Defesa, remaneja cargos em comissão e substitui cargos em comissão do Grupo-Direção e Assessoramento Superiores - DAS por Funções Comissionadas do Poder Executivo - FCPE. Disponível em: http://www. planalto.gov.br/ccivilo3. Acesso em 11 fev. 2017.

Kent, S. 1967. Informações estratégicas. Trad. Cel. Hélio Freire. Rio de Janeiro: Biblioteca do Exército.

Lowenthal, M. M. 2009. Intelligence: from secrets to policy. 4th. ed.Washington: CQ Press.

Platt, W. 1974. A produção de informações estratégicas. Trad. Álvaro Galvão Pereira e Heitor Aquino Ferreira. Rio de Janeiro: Biblioteca do Exército.

Santos, A. R. e outros. 2002. Defesa Nacional e Inteligência Militar. Disponível em http://www.senado.gov.br/comissoes/ccai/07-Quarta\%20Parte.pdf. Acesso em 3 jul. 2016.

Shulsky, A., Schmitt, G. 2002. Silent warfare: understanding the world of intelligence. 3rd. ed. Washington: Brassey's.

United States. Department of Defense. 2011. DOD. Dictionary of Military and Associated Terms. JP1-02. Disponível em: http://www.people.mil/Portals/56/ Documents/rtm/jp102.pdf. Acesso em 3 jul. 2016.

. Department of Defense. 2017. DOD. Dictionary of Military and Associated Terms. Disponível em: http://www.dtic.mil/doctrine/new_pubs/dictionary.pdf. Acesso em 31 mar. 2017. 


\section{NOTAS}

1. A Lei $n^{\circ} 97 / 1999$ foi atualizada pela Lei Complementar $n^{\circ} 136$, de 25 de agosto de 2010 .

2. APND e a END, atualizadas em 2012, foram aprovadas pelo Decreto Legislativo $\mathrm{n}^{\circ} 373$, de 25 de setembro de 2013. Em março de 2017, o texto com a PND e a END atualizadas em 2016 foi disponibilizado no sítio do Ministério da Defesa. Até a data de conclusão desse ensaio o novo texto ainda não tinha sido apreciado pelo Congresso. A forma como a Inteligência é apresentada nessa versão suscita questões que, provavelmente, serão tema de outros estudos.

3. Os decretos que modificaram a estrutura regimental do MD foram: Dec. $n^{0} 3.466 / 2000$, Dec. $n^{\circ} 4.735 / 2003$, Dec. $n^{\circ}$ 5.201/2004, Dec. $\mathrm{n}^{\mathrm{o}}$ 6.233/2007, Dec. $\mathrm{n}^{\mathrm{o}} 7.364 / 2010$, Dec. $\mathrm{n}^{\mathrm{o}} 7.974 / 2013 \mathrm{e}$ Dec. $\mathrm{n}^{\mathrm{o}}$ $8.978 / 2017$.

4. Conferência apresentada pelo Gen. Div. Aloísio dos Santos - Diretor do Departamento de Inteligência Estratégica do MD em 2002 - e por outros oficiais generais integrantes da área de Inteligência das FA, no Seminário Atividades de Inteligência no Brasil: Contribuições para a Soberania e a Democracia em novembro de 2002.

5. A Portaria Normativa $n^{\circ} 295 / M D$, de 3 de julho de 2002 , foi assinada pelo então Ministro da Defesa Geraldo Quintão, alguns anos depois da criação do SISBIN.

6. Estatura estratégica - termo utilizado por Sherman Kent para caracterizar a soma total de meios de coação e dissuasórios que cada país possui e sua vontade e capacidade de usá-los.

7. Constituição Federal, 1988, art. $3^{\circ}$.

8. O SISBIN é composto por 38 órgãos de 16 diferentes ministérios. 


\section{A ATIVIDADE DE INTELIGÊNCIA NO MINISTÉRIO DA DEFESA: UMA PROPOSTA DE REFORMA}

\section{RESUMO}

Este ensaio pretende analisar as modificações ocorridas na estrutura organizacional e nas atribuições das áreas relacionadas às atividades de Inteligência Estratégica e de Inteligência Operacional no âmbito do Ministério da Defesa, desde a sua criação em 1999 até a publicação da última reestruturação em fevereiro de 2017. A partir daquela análise, propor modificações naquela estrutura que propiciem melhores condições para a execução da atividade de inteligência estratégica.

Palavras-chave: Defesa; Inteligência; Inteligência Estratégica; Ministério da Defesa.

\section{ABSTRACT}

This paper discusses the changes that have occurred in the organizational structure of the Ministry of Defense and in the attributions of the Ministry's areas related to Strategic Intelligence and Operational Intelligence activities since its creation, in 1999, to the publication of the last restructuring decree, in February 2017. From that analysis, to propose modifications in that structure that propitiate best conditions to the performance of Strategic Intelligence .

Keywords: Defense; Intelligence; Strategic Intelligence; Defense Ministry. 